\title{
Chapter 5 \\ Studying Networks Geographically: World Political Regionalization in the United Nations General Assembly (1985-2010)
}

\author{
Laurent Beauguitte
}

The study of networks from the viewpoint of a geographer does not mean studying geographical networks as technical infrastructures, especially when one is interested in geopolitical phenomena. It means that the relational nature of a given spatial phenomenon seems to demand a specific approach, that is, a network one, and that formalization via a graph (a set of nodes, a set of links between these nodes, and some attributes) allows discovering unrevealed aspects of a sociospatial fact. The study of networks often means adopting an interdisciplinary posture, applying tools and methods developed in other academic fields, and conducting solid conceptual analysis. For instance, whereas distance and centrality are useful concepts in both geography and social network analysis, their definition and implications for research remain quite different and need to be adapted from one academic field to another to remain efficient and relevant.

This chapter presents results on the political regionalization process on a world scale, a process understood as the reinforcement of supranational structures based on geographical proximity. I presume that political actors, and especially state representatives in intergovernmental organizations, are constrained to work more and more often supranationally because of the globalization process, a process that can be understood neither solely nor primarily as an economic or financial phenomenon but rather as an increase in global issues demanding global responses and a governance shift (e.g., global warming, migrations, and energy). Although much has been published on economic regionalization since the 1990s (e.g., Mansfield \& Milner, 1999), the political aspects have been quite neglected, and when they are studied, especially in international relations, the approach is mainly qualitative and purely conceptual (Barnett \& Duvall, 2005; Diehl, 2005). The approach investigated in this chapter is taken from the behavioral school of international relations: If political regionalization is occurring, it should be possible to measure it, produce indicators,

L. Beauguitte $(\bowtie)$

UMR IDEES, CNRS, 7 rue Thomas Becket, 76821 Mont Saint-Aignan, France

e-mail: laurent.beauguitte@cnrs.fr 
and validate the hypothesis by using quantitative and reproducible methods. Because a political process by nature involves relations among actors, network analysis appears to be a relevant tool to investigate this regionalization.

I begin with a short overview of network analysis in geographical studies because the similarity in vocabulary between the sciences can hide a large gap in methods, procedures of validation, and questions of research. Opportunities for political geography will be highlighted. Because techniques of network analysis are rarely used in geopolitical studies nowadays, the strengths and relevance of political geography will be underscored. The next section presents the main hypothesis, the field of observation (the United Nations General Assembly from 1985 until 2010), and the methodological choices made to study world political regionalization. The final section presents the main results obtained and underlines the relevance of network analysis for investigating questions of political regionalization. If tools of network analysis prove valuable in highlighting processes of innovation, they can also produce innovative results when brought to bear on many research questions. Geographical logics of coalition and policy-making, which in this chapter are investigated on a world scale but can be studied from a multiscalar perspective, can greatly benefit from such input (Hafner-Burton, Kahler, \& Montgomery, 2009).

\section{Network Studies in (Political) Geography: A Quick Refresher}

Because I am a geographer, my academic training involved a specific relationship with the network approach, and I feel it necessary to describe geographical network analysis briefly before highlighting the opportunities that network analysis offers in geopolitical investigations. There is no pretense that this description is exhaustive, and it is based largely on a French perspective. Network literature has grown so voluminous and diverse since the mid-1990s that it has become nearly impossible for one individual to follow all the developments - although an overview of relations between complex network studies and geography was recently proposed (Ducruet \& Beauguitte, 2013). This chapter therefore offers not a definitive state-ofthe-art treatment of geographical networks but rather some observations on the disciplinary biases inherent in network approaches as well an appeal for dialogue between disciplines. Since the inception of political geography, its practitioners, like those of international relations, have intensely investigated the question of power. Although many definitions of this central concept have been proposed, the canonical one by Dahl (1957) remains one of the most elegant: "A has power over B to the extent that he can get B to do something that B would not otherwise do" (pp. 202-203). This definition underlines the strong relational nature of power. It cannot be considered an attribute of an individual actor; it implies relations between actors and at least dyadic examinations. 


\section{Network as a Fashionable Metaphor}

Not surprisingly, the term network is polysemous. Its three most widely accepted definitions can be found in current geographical literature: network as a metaphor; network as a technical infrastructure; and-similar to, but distinct from, network studies in the strict sense-network as relational flows between places. The predominant definition of the word is its metaphorical one: A network is a social process (migratory network) or a system of relations (network of cities) that crosses borders. It is fluid, moving, and dynamic. In this sense the network is always the opposite of an enclosed and stable territory. The study of networks from this perspective does not involve any methodological choice, and the term network could simply be replaced by another (Glückler, 2013; Grabher, 2006). In political geography this metaphorical usage is especially strong given the presumed weakening of the level of the state, which is being overwhelmed by transboundary movements and the supranational nature of financial and economic actors. P. Taylor's publications of the Globalization and World Cities Research Network ${ }^{1}$ are quite representative of this trend, which moves away from the state level to consider mainly relations among the so-called world cities. Although many of these papers are quite interesting from a thematic perspective, network remains an emblematic word that implies neither conceptual nor methodological change. More interesting for my topic is the coexistence of two intersecting research traditions, one dedicated to technical networks and the other dedicated to flow studies.

\section{Two Geographic Traditions: Infrastructure Networks and Flow Studies}

As for the nonmetaphorical network, two main approaches exist in current geographical research: technical networks and flow studies. Studies of infrastructure networks (transport, energy, communication) were predominant starting with the seminal doctoral dissertation by Kansky (1963) until the middle of the 1990s and remain at the core of network studies in geography today. Although a minority of geographers tried to mix methods and propose new ways to study transportation networks (Ducruet, Ietri, \& Rozenblat, 2011; Gleyze, 2007), the canonical tradition using the series of indices by Kansky (different ratios between the number of edges, the number of vertices, and the number of cycles derived from graph theory) prevails. It should be noted that in the vast majority of cases, networks are planaroften valued and nondirected - a characteristic that may help explain the lack of methodological dialogue with social network analysis, in which a network is more often Boolean, directed, and nonplanar. Even though some methodological

\footnotetext{
${ }^{1}$ http://www.lboro.ac.uk/gawc/
} 
innovation has taken place, especially with respect to place accessibility and multilevel analysis (Mathis, 2003), dialogue with other social sciences remains the exception rather than the rule. However, these studies can provide valuable input for political geography because the structure and characteristics of technical networks can reveal social, economic, and spatial patterns. In what became for decades the reference handbook of network analysis in geography (Haggett \& Chorley, 1969), one small example puts into perspective the physical aspects, socioeconomic variables (e.g., urbanization, hierarchy of cities), and indices of road and rail networks (pp. 88-89). The density and connectivity of technical networks are factors that reveal the level of regional or national wealth that can explain given patterns of relations among these actors.

Another trend in geographical research is relational by nature because it involves the study of flows between places. The use of a model inspired by laws of gravitation became a convenient tool in the 1960s and has been common since then to study and model patterns of interaction (Nystuen \& Dacey, 1961; Tobler, 1970). Based on valued flows (goods, communication, migration), the techniques developed did not involve any dialogue with social network analysis. Note also that this literature barely makes explicit reference to the term network. However, several recent works by physicists draw on these interaction models mixed with complex network approaches and generally demonstrate that the two methods produce complementary results (Gorman et al., 2007). Interest in such approaches for political geography cannot be underestimated; they are able to reveal, for instance, preferential relations as well as barriers between pairs of actors. Mixing tools from flow studies and network analysis clearly appears promising for investigating globalization processes at multiscalar levels (Van Hamme \& Grasland, 2011).

\section{Some Recent and Welcome Changes}

The soaring number of physicists and computer scientists in the network field since the 1990s has changed the landscape on two fronts. First, some geographers were quick to adopt new measurements from related works (clustering coefficient, power law degree distribution). Rozenblat's papers on economic and transport relations between world cities are good examples of this imitation process (Rozenblat \& Melançon, 2007). This early acceptance can be explained by the not-so-new character of the scale-free network as a power law distribution, which is a common and well-known process in several social sciences (e.g., rank distribution of cities in urban geography, Zipf's word distribution in textual analysis). It must also be mentioned that the conclusions offered in the works on world cities remain classic yet are somehow deceptive: Using so-called innovative methods to show that Paris, London, New York, and Tokyo are the main world cities appears to contribute little to geographical knowledge (Rozenblat \& Melançon, 2007). More noteworthy is the interest some physicists are taking in spatial networks and models and the methods proposed to analyze them (Barthelemy, 2011; Gastner \& Newman, 2006). Methods 
from social network analysis were less widely adopted by geographers, but several recent papers have indicated the use of the block model and equivalence (Drevelle, 2013), density and nodes centrality measures (Comin, 2009; Maisonobe, 2013), and k-cores to reveal a world center-periphery structure (Van Hamme \& Pion, 2012). Once again, the emerging hybridization of disciplinary traditions appears quite interesting for geopolitical studies. It does not mean that network analysis is the only way to study conflicts or patterns of relations between actors, whatever the level of analysis. However, it is worth considering that, for some specific questions, network analysis can reveal unexpected facts and trends.

In summary, network analysis appears to be of major interest for geopolitical studies, especially when one is investigating power and hierarchy among actors. In the following sections I describe the investigation of patterns of relations among actors in the United Nations General Assembly (UNGA), using network analysis to test whether political regionalization is taking place on a world scale.

\section{A Relational Approach to the United Nations General Assembly}

Since the 1950s, and especially at the zenith of the behaviorist school of international relations (1960s and 1970s), a long tradition of United Nations (UN) studies has explored relations between actors, consequences of decolonization, the rise of ideological groups advocating a more equitable economic system than the existing one, the socializing effect of UN sessions, and the specific position of states in the UN system (although this list is far from exhaustive). The existence of blocs, regional or ideological, in the UN system, particularly in the UN General Assembly, triggered a profusion of books, reports, and papers, mainly in the Anglophonic academic sphere. Proposing even a short overview of this literature would hardly be feasible, even if the scope were limited to quantitative approaches (for a good starting point, see Beauguitte, 2011).

The UNGA is of significant interest for researching political geography. During a session, nearly all the world's political actors exchange ideas, discuss problems, confront each other, and attempt to assemble the pieces for more efficient world governance. Network analysis appears relevant mainly because decisions in the UNGA involve discussions, negotiations, and relations between actors, and there are documents available from which to draw the relational pattern between these actors. Of course, data collected reflect only the final step of dialogue, and the ways to achieve agreement among actors are generally unknown. At least three mechanisms have been identified in the literature: free agreement (two actors are likeminded on a specific topic), bargaining (A votes yes on this topic if B votes yes on another topic), and pressure (A must vote this way to get financial support from B). A well-known example of bargaining is the relationship between the Arab League and the African Union. Since the 1970s, the African Union has supported Arab 
League positions on Palestine, whereas the Arab League has supported the African Union's position on economic development. Examples of pressure are less welldocumented but are occasionally mentioned in the minutes of the meetings, albeit without precise targets. Before examination of the voting behavior and speech patterns in the UNGA, a short review of the UN system seems appropriate to justify some methodological choices.

\section{Studying the UN System from a Geographical Point of View}

The UN organization can be considered a relational system and a bureaucratic organization at the same time. First, positions of actors in the UN system depend on the relative positions of other actors. Moreover, an actor's behavior in one specific organ can in certain cases be explained by the position of this actor in another organ of the UN system. One familiar example is the voting behavior of the United Kingdom and France in the UNGA - they often vote differently from other member states of the European Union (EU) - behavior that can be explained only by their permanent member status in the Security Council. Another relational aspect relates to the possibility of action in the UN system in general and in the UNGA specifically: Any decision involves a dense network of relations with other actors, with all decisions being adopted by consensus or majority.

But the UN system is also a bureaucratic organization where the behaviors of actors are highly predictable (needed to strengthen cooperation), where stability outweighs evolution, and where reform is always a long and costly process. One of the most famous examples of this bureaucratic aspect is the reform of the Security Council, which generated hundreds of speeches, reports, and recommendations but not one single concrete decision.

Since its creation, the UN system has been extensively studied by academics, especially by North American academics in the fields of political science and international relations - the U.S. government has always paid a great deal of attention to UN activities and has financed numerous research projects. Geographers have paid scant attention to the UN's decision-making processes. However, at least two aspects are of particular interest: the geography of cooperation and conflict, and scale issues related to daily operations. Because nearly all states are represented in the UNGA, this institution allows one to observe patterns of cooperation on a worldwide scale, from both dynamic and thematic points of view, and studying voting behavior provides some valuable geopolitical input.

A brief explanation of the purpose and function of the UNGA seems warranted at this point. The aim of the UNGA, according to the UN Charter signed in 1945, is to "consider the general principles of cooperation in the maintenance of international peace and security, including the principles governing disarmament and the regulation of armaments" (Charter of the United Nations, Article 11) and to initiate studies and make recommendations for the purpose of (a) promoting international cooperation in the political field and encouraging the progressive development of 
international law and its codification; (b) promoting international cooperation in the economic, social, cultural, educational, and health fields; and (c) assisting in the realization of human rights and fundamental freedoms for all without distinction as to race, sex, language, or religion (Charter of the United Nations, Article 13).

When a member state, a regional group, or an ad hoc group of states submits a resolution proposal to the General Assembly, there can be one of two outcomes. The first and most frequent one is the resolution's adoption by consensus without any vote. Depending on the session, between two thirds and three quarters of all resolutions are adopted by consensus. A vote indicates a controversial issue, and member states have four options (only member states are able to vote): vote yes, abstain, vote no, or abstain. The last option often indicates a small and/or failed state that cannot obtain a permanent delegation in the UNGA. It should also be noted that nearly all states are UNGA members: The Holy See and the State of Palestine have observer status (they can sponsor a resolution but cannot vote), and Taiwan is the only independent state not recognized by the UN system, a situation due to the strong and persistent opposition of China.

\section{Geographical Voting Patterns in the UNGA}

Studying votes in the UNGA has had a long academic tradition since the seminal paper by Ball (1951). The main hypothesis is that states that vote the same way on a vast range of topics are supposedly politically close and like-minded. Kissack (2007) noted that studying votes has advantages as well as drawbacks, and among the latter is the inability to infer any cooperative behavior from results obtained. In other words, in an arena where many resolutions are ritually adopted year after year over several decades, two states can exhibit the same voting behavior without having any actual relation. However, in an arena where two thirds of the resolutions are adopted by consensus, putting an issue up for vote already indicates a lack of consensus. Whereas a similar vote does not necessarily imply a close relation, a dissimilar vote conversely indicates opposition between two actors. When dozens of votes are considered, similar voting patterns can infer a relation between a pair of actors. Moreover, the autonomy of actors is not equally distributed: Some delegations have dozens of members (e.g., diplomats, lawyers, and counselors), whereas delegations from the poorest countries have only two to five members. It is obviously difficult for the small delegations to study all proposed resolutions, to consider their legal implications, and so on, and voting behavior will depend on group directives rather than on national orientation.

For the two sessions considered here (the 42nd and 63rd), voting results were selected according to (a) resolutions and (b) member states. First, tables recording all voting results per session were made from the UNBISnet website, which provides all details of states' behavior per resolution. ${ }^{2}$ Then, near-unanimous resolutions

\footnotetext{
${ }^{2}$ http://unbisnet.un.org/
} 
were deleted (less than $5 \%$ of no votes or abstentions). The resolution-based selection was motivated by the presence of very specific resolutions on Israel for which only Israel and the United States voted against or abstained. These two states are clearly peripheral in the UNGA, and including these votes would not provide any supplementary information. The second selection, based on member states, comprised those states that were often absent and not able to vote. Keeping the threshold used in previous studies, I chose to delete states that did not participate in at least $30 \%$ of the votes. Failing to omit these states would produce a group lacking political consistency. The final tables included 158 states and 145 resolutions for the 42nd session (1987-1988) and 178 states and 68 resolutions for the 63rd session (20092010). These basic measurements are congruent with the general trend in the UNGA in this period: a rising number of member states (with the addition of former Eastern-bloc countries in the 1990s and many small states in the 2000s) and a diminishing number of resolutions put to a vote.

Several network approaches can be used to study voting behavior in the UNGA. The most common method is to create a multibipartite state-resolution graph and to transform it into a state-state similarity matrix with range values from 0 (two states always vote in a different way) to 100 (two states always vote the same way). One issue concerns the threshold process because finding a value suitable for different sessions seems challenging. The solution proposed by Beauguitte (2011) was to choose the same statistical threshold for all similarity tables in order to allow comparison. However, transformation from continuous to discrete values remains quite unsatisfactory. Although some authors proposed this approach in the 1960s (Lijphart, 1963), multivariate analysis (mainly principal component analysis) soon became the canonical method of handling this data.

An alternative option that allows keeping link weights is to adopt a variation of the CONCOR method adapted for valuable matrices; the classification procedure groups together states that have the same relational profile. Figure 5.1 shows the regional structure based on voting behavior before the end of the Cold War (42nd session, 1987-1988), and Fig. 5.2 reflects the situation in 2010 (63rd session, 20092010). The considerable cluster inertia is quite surprising but confirms results obtained in previous research (Voeten, 2000). Even today, there is one Northern bloc in opposition to one Southern and Eastern bloc. In 2009 the East appeared smaller because eastern European countries began to behave like western onesadhesion or application to the EU - but the main fracture between developed and less developed countries continued to be the dominant pattern. The voting pattern of Turkey, one of the few countries showing a marked change, was becoming more and more like that of western countries. The cluster inertia is also related to the structure of resolutions voted upon in the UNGA. The Israeli-Palestinian conflict is the subject of more than one third of all resolutions voted upon in each session. Regarding this issue, the West strives for a balanced stance, whereas other members share a pro-Palestinian approach, which partly explains their cohesiveness. In 2009 there appeared a tiny group of small developing island states that tended to vote like Southern-bloc states, except when resolutions concern global warming. 


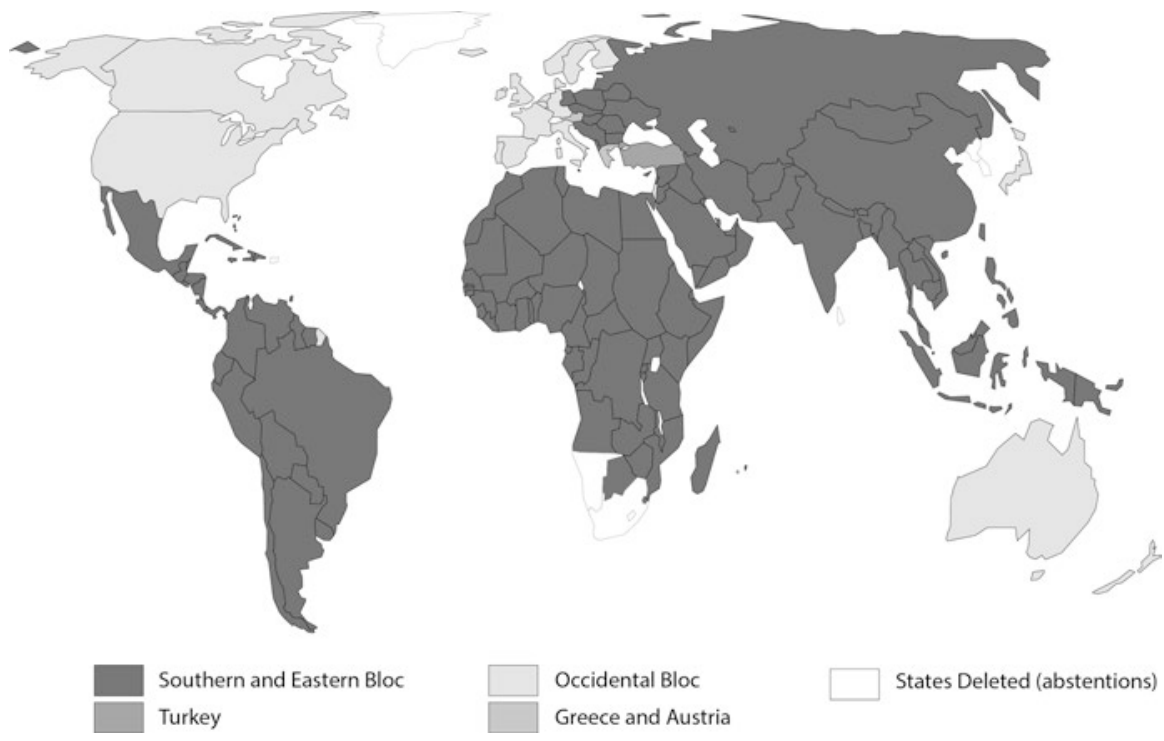

Fig. 5.1 Political regions in the UNGA in 1987 (42nd session). From UNBISnet (Performed by Philcarto. Design by author)

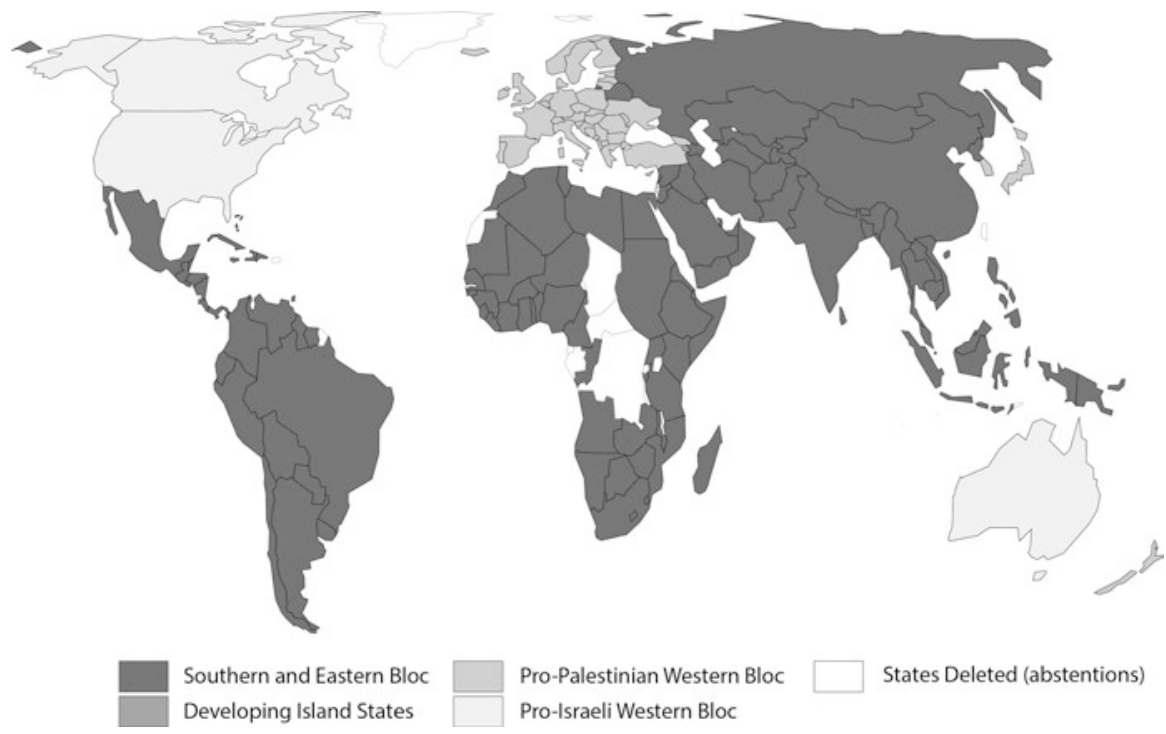

Fig. 5.2 Political regions in the UNGA in 2009 (63rd session). From UNBISnet (Performed by Philcarto. Design by author) 
This clustering approach is of particular interest because it is able to sum up thousands of statements, speeches, and resolutions in order to produce an artificial map of political regions. The map does not necessarily signify that two member states in the same group always behave in the same way or share common views on the vast range of topics examined in the UNGA. However, it does provide an initial delineation that should be kept in mind for in-depth study.

Other approaches appear valuable and can provide relevant results, such as investigating resolutions' sponsors by topic or similarities among resolutions to see whether or not the same type of resolution (on human rights or economic development) tends to produce highly interconnected graphs. However, studying voting behavior provides only a partial picture of relational patterns in the UNGA because only one third of resolutions are included.

Whereas studying voting behavior is a traditional way to view relations in the UNGA, the study of speeches remains less developed even though the General Assembly can be considered an arena of words rather than decision-making. Each year, representatives from nearly all countries (Taiwan excepted) issue statements on a broad range of issues, and these speeches can be considered the official position of those states' governments. But states are not the only speakers, and the study of speeches supports multiscalar analysis.

\section{Speech Dynamics in the UNGA: A Network Approach}

Various individuals make statements in the UNGA: representatives of states (nearly $80 \%$ of all statements during a session for the period under consideration), representatives of groups, of institutions from the UN system, and, less often, representatives from NGOs (e.g., the Red Cross) or institutions external to the UN system (e.g., the European Commission). In the last two decades, a change in speech dynamics has occurred. Groups issued more and more statements on a growing range of topics, and states' representatives have supported their statements more and more often, two patterns that could be a relevant indicator confirming the political world regionalization hypothesis. Minutes of meetings from 1990 to 2010 were reviewed to collect all speeches that affirmed "state A supports group $a$," and these data were studied as bipartite graphs. Occurrences of such speeches were transformed into a state-group matrix in which each case indicates the number of times a state A supported a statement made by a group $a$. The poor quality of documents from older sessions prevents automatic word-searching, and data-gathering was therefore manual and time consuming. 
Table 5.1 Main properties of bipartite state-group network

\begin{tabular}{lccccc}
\hline Session & No. of states & No. of groups & Density & Diameter & Components \\
\hline $45(1990-1991)$ & 10 & 3 & .367 & 3 & 2 \\
$51(1996-1997)$ & 52 & 6 & .196 & 6 & 2 \\
$57(2002-2003)$ & 54 & 14 & .098 & 7 & 5 \\
$63(2009-2010)$ & 100 & 14 & .129 & 6 & 3 \\
\hline
\end{tabular}

Source: UNGA verbatim records

\section{Statements by Regional Groups and States}

Table 5.1 provides a general picture of this phenomenon. The increase in the number of states that support a group's statements is quite impressive (from 10 to 100 in 20 years), whereas the progression of groups is less marked (from 3 to 14).

Before the graphs from Fig. 5.3 are interpreted, one distinction is necessary regarding the type of groups investigated. Some groups can be called ideological because they defend specific points of view on topics examined in the UNGA, whereas others can be labeled regional because their main ambition is integration at a supranational level-although some regional formations may indeed be based on ideological considerations. (The EU, for instance, is based mainly on the liberal free-market ideology.) Among the initial groups, the Nonaligned Movement (NAM) and the Group of 77 (now called the Group of 77 plus China) are emblematic of the 1970s at the UNGA, with NAM supporting an alternative political path between capitalism and socialism and the G77 promoting a new and less disparate world economic order. These two groups remain active, giving voice to the weakest states and advancing their claims.

In 1990 (Fig. 5.3, Session 45) the situation was quite simple: The European Commission was the only group whose statements were regularly supported by its member states. Although the EC was not the only group to make statements, individual states did not support statements made by other groups. The other two supported groups (G77 and the least developed countries) can be considered ideological because they do not promote a regional integration process but defend a more general point of view based on uneven economic development.

Six years later (Fig. 5.3, Session 51) the situation was not so different, although there were more member states that supported groups' statements. Although EU member states often supported EU statements, most of the links in the component illustrated on the left reflected ideological considerations (degree equal to 6 for NAM, degree equal to 9 for the G77 plus China). Nevertheless, the increase in the number of regional groups in the strict sense (Latin America and the Caribbean, the Rio Group, and the Organization of African Unity) was notable, and some member states chose to support one group or another, depending on the topic under consideration. 


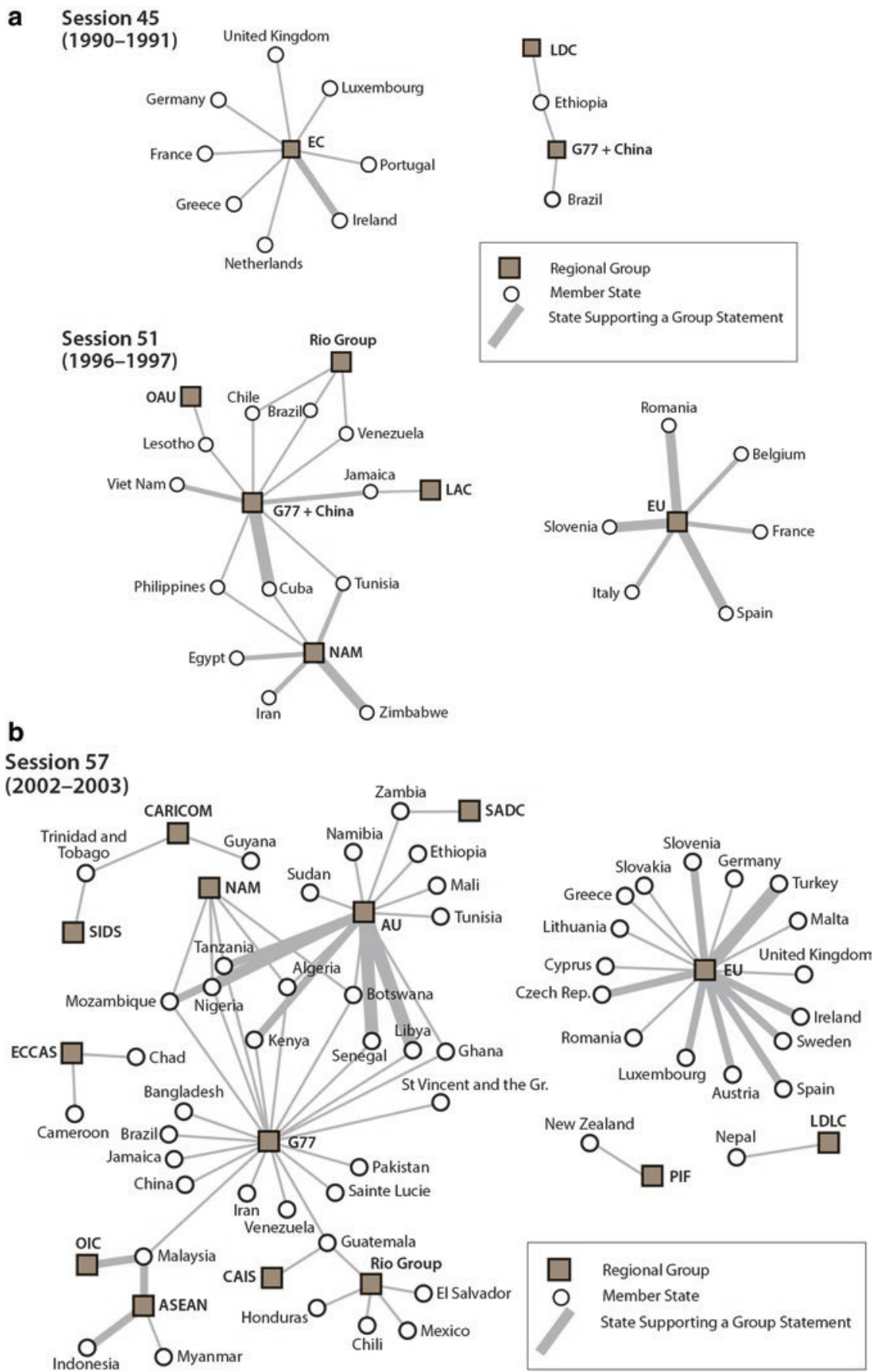

Fig. 5.3 Bipartite UNGA state-group graphs. ASEAN Association of Southeast Asian Nations, $A U$ African Union, CAIS Central American Integration System, CARICOM Caribbean Community, EC European Commission, ECCAS Economic Community of Central African States, EU European Union, 
The 57th session (2002-2003) shows the growing importance of regional groups for all member states, European or otherwise. The G77 plus China maintained its central position, and NAM moved to a more peripheral position. All other groups that appear affirmed regional integration as one of their main objectives. Once again, the EU was a component isolated from other countries and included only member states (and candidates). This picture confirms previous results according to which the EU is simultaneously one of the most cohesive groups in the UNGA and one of the most isolated because it is unable to attract support from other actors (Gowan \& Brantner, 2008). The situation in 2009- not reproduced here because the density of the graph renders it unreadable-confirms this evolution: the rising importance of regional groups, the rising number of states supporting several groups depending on the topic examined, and the cohesiveness and isolation of the EU. Further studies are needed, especially to investigate concrete mechanisms of cooperation that groups set up to achieve these results. One can assume that this trend reflects an increasingly pressing need for member states to see that taking action through a supranational framework is more efficient than taking action as individual member states. However, major powers - the best example being the United States, which never appears on these graphs-do not necessarily need regional groups. When political regionalization occurs, it is primarily for actors unable to influence world decisions by themselves. Another question concerns how the UNGA itself functions. As regional groups become more active (sponsoring resolutions, making statements, and collaborating with one another), will the organization be able to change its procedures to take this dynamic into account or will it remain a strictly international organ? The fact that the EU recently gained a higher participation status - EU representatives (rather than representatives of the state leading the EU) can now make statements and propose resolutions - indicates that organizational change is possible to reinforce the role of regional groups. ${ }^{3}$

\section{From Empirical Observations to Models of Cooperation and Regionalization}

A complementary approach to this discursive regionalization dynamic is to build ideal types based on the expected behavior of actors instead of measuring the expansion of phenomena from one session to the next. This exercise is interesting principally because it identifies the relation between actors and their motivations and

Fig. 5.3 (continued) G77 Group of 77, $L A C$ Latin America and the Caribbean, $L D C$ Least Developed Countries, $L D L C$ Least Developed and Landlocked Countries, NAM Nonaligned Movement, OIC Organization of Islamic Cooperation, OAU Organization of African Unity, PIF Pacific Islands Forum, SADC Southern African Development Community, SIDS Small Island Developing States (Source: UNGA verbatim records. Design by author)

\footnotetext{
${ }^{3}$ http://www.unbrussels.org/general-assembly-grants-eu-higher-participation-status.html (retrieved June 16, 2014)
} 


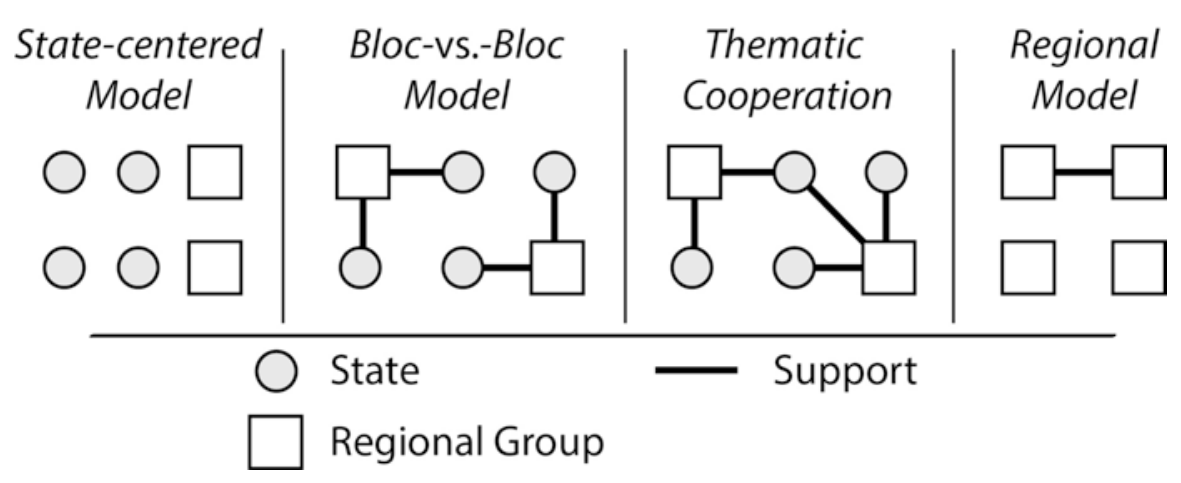

Fig. 5.4 Theoretical models of regional cooperation (Design by author)

connects this trend to conceptual inquiries in political geography and international relations. Of course, as always, models are not claimed to represent reality in all its dimensions. They are propositions of a simplified structure that depicts main relations between prominent actors. A model can also serve as a guideline to relate actual evolution to conceptual inquiries regarding relations between actors on a world scale.

This regionalization trend poses two main questions, one about cooperation and the other about the scalar level of decision-making. From a thematic and geopolitical point of view, the rise in regional groups can be regarded as the expression of political regionalization based on cooperation between actors - primarily, but not exclusively, national ones. This concept is clearly related to globalization as regionalization emerges as a process in which nation states within geographic proximity take collective measures to cope with problems of global governance...the more regionalized the world, the more necessary, enabled and willing for regions to construct connections with each other [sic]. (Song, 2007, p. 67)

This process does not mean the end of bilateral relations or the end of the state level, but it does involve a new paradigm for comprehending world structures (Chen, 2005). One main challenge in the near future will be to improve coordination of national interests and group dynamics and to engage the main powers (United States, Russia, or China) in this process. The multilevel scale of governance inside international organizations also offers a new angle of research. Although member states continue to get their own agendas into the international forum, their actions are increasingly constrained by supranational structures. Figure 5.4, which is based on both theoretical considerations and the data analysis presented in Table 5.1, attempts to model this process of regionalization, in which four different types of cooperation emerge.

The four hypothetical graphs in Fig. 5.4 show the evolution from a pure statecentered situation to an ideal regional configuration. These graphs sum up three key hypotheses on world political regionalization: (a) the presence of regional groups is increasing, (b) states are using regional groups more and more often to achieve their aims, and (c) cooperation between regional groups is rising. Of course, the hypotheses 
apply only if the globalization process continues, change that should not be taken for granted. One can certainly envision a process of shrinking globalization in which ever more barriers are erected at the state level. The rising anti-European feeling serves as a reminder that history does not stand still and that social processes are far from being linear or predictable.

In the first graph on the far left, several groups make statements and member states make statements, but there are no links between these two categories of actors. The second graph depicts conflict between two groups that have the support of their respective members: The EU-versus-the-rest-of-the-world configuration observed in recent years closely resembles this pattern. It is also the model that best lends itself to partitioning the political world. The third graph reflects a situation in which member states, depending on the topic, choose to support one group or another, which happens with increasing frequency in the UNGA in the case of the South American and Pacific island states. The final graph models a situation in which a process of cooperation emerges between regional groups and in which all statements by the states assume a supranational scale. This ideal is still a long way off because national interests are predominant among the most powerful states.

Although these models can be helpful for highlighting processes in a specific arena and for providing points of comparison, they portray only one of many possible progressions. From a thematic point of view, political regionalization is mostly a weapon of the weak. Since the 1970s, groups have been used by small, recently decolonized, and peripheral member states in the UNGA, and it is not by chance that the United States and Russia are not represented in the graphs in Fig. 5.3. Three major kinds of group relations can be found in the UNGA. Some states do not need them (United States, Russia), some powerful states use groups only to reinforce their interests (France, United Kingdom, and China), and some states need groups to be heard (the least developed states). It seems that two kinds of political regionalization are distinguishable: voluntary and constrained. The first includes wealthy states aiming to reinforce their position and internal cohesiveness (the EU); the second subsumes states too weak to influence decisions by themselves. Qualitative methods are needed to confirm this hypothesis because network analysis does not allow differentiating these two types of groups.

\section{Concluding Remarks}

Is network analysis necessary? Did the results obtained in this study need these techniques and methods or can they be obtained by other means? The clustering method used to produce the maps in Figs. 5.1 and 5.2 is not completely satisfactory, and other statistical multivariate techniques could easily be applied to data on voting behavior. The results arrived at are congruent with those produced by other means, but the interpretation of classes remains more difficult than with a principal component analysis, for example. Where scales of speeches are concerned, network analysis appears much more relevant than votes and reveals patterns of interaction 
not easily identifiable by other means. So the answer is partly yes: Network analysis, like any other technique, is not a one-size-fits-all solution. It is able to produce unexpected discoveries in geopolitical research.

From a geopolitical perspective network analysis seems a useful tool with which to investigate regionalization processes, for these processes reinforce links - either cooperative or conflicting - between several types of actors. If the UNGA comprises mainly states and groups, then several other forums, notably the major UN-organized conferences, involve very different actors (e.g., firms, NGOs, experts), and a network approach would be helpful to improve the understanding of contemporary dynamics in world governance. If geography matters, it is primarily because spatial proximity appears to favor cooperation. Furthermore, patterns of relations create political regions of like-minded actors, and discontinuities are likely to appear between these regions. For instance, a recent study on human rights issues have revealed the gap between Europe, Africa, and the Middle East (Beauguitte, 2012).

Network analysis is ultimately a powerful way to communicate results, although the readability of graphs needs improving (Bahoken, Beauguitte, \& Lhomme, 2013; Henry, Fekete, \& McGuffin, 2007). Last but not least, network analysis also represents an excellent way to cross disciplinary boundaries and encourage discussion among researchers.

\section{References}

Bahoken, F., Beauguitte, L., \& Lhomme, S. (2013). La visualisation des réseaux. Principes, enjeux et perspectives [The visualization of networks: Principles, stakes and perspectives]. Groupe f.m.r. working paper. Retrieved from http://halshs.archives-ouvertes.fr/docs/00/83/99/05/PDF/ fmr18_visualisation.pdf

Ball, M. (1951). Bloc Voting in the General Assembly. International Organization, 5, 3-31. doi: $10.1017 /$ S0020818300029805

Barnett, M., \& Duvall, R. (Eds.). (2005). Power in global governance. Cambridge, UK: University Press.

Barthelemy, M. (2011). Spatial networks. Physics Report, 499, 1-101. doi:10.1016/j. physrep.2010.11.002

Beauguitte, L. (2011). L'Assemblée générale de l'ONU de 1985 à nos jours. Essai de géographie politique quantitative [United Nations General Assembly of 1985 in our days: Essay on quantitative political geography] (Doctoral dissertation, University of Paris 7). Retrieved from http://hal.archives-ouvertes.fr/docs/00/63/44/03/PDF/These_Beauguitte_2011_ONU_et_ Systeme_Monde.pdf

Beauguitte, L. (2012). L'ONU contre la peine de mort. La puissance normative de l'UE en question [The UN against the death penalty. The question of the normative power of the EU]. L'Espace politique [online], 18. doi:10.4000/espacepolitique.2432

Charter of the United Nations. (1945). http://www.un.org/en/sections/un-charter/un-charter-fulltext/index.html

Chen, Z. (2005). NATO, APEC, and ASEM: Triadic interregionalism and global order. Asia Europe Journal, 3, 361-378. doi:10.1007/s10308-005-0005-7

Comin, M. N. (2009). Réseaux de villes et réseaux d'innovation en Europe: structuration du système des villes européennes par les réseaux de recherche sur les technologies convergentes [Networks of cities and networks of innovation in Europe: The structuring of the European 
system of cities through research networks dedicated to converging technologies]. (Doctoral dissertation, University Paris I, Panthéon-Sorbonne).

Dahl, R. A. (1957). The concept of power. Behavorial Science, 2, 201-215. doi:10.1002/ bs. 3830020303

Diehl, P. F. (2005). The politics of global governance: International organizations in an interdependent world. Boulder: Lynne Rienner.

Drevelle, M. (2013). Structure des navettes domicile-travail et polarités secondaires autour de Montpellier [Structures of commuting traffic and secondary polarity around Montpellier]. $M @$ ppemonde, 107. Retrieved from http://mappemonde.mgm.fr/num35/articles/art12304.html

Ducruet, C., \& Beauguitte, L. (2013). Spatial science and network science. Review and outcomes of a complex relationship. Networks \& Spatial Economics, 14, 297-316. doi:10.1007/ s11067-013-9222-6

Ducruet, C., Ietri, D., \& Rozenblat, C. (2011). Cities in worldwide air and sea flows: A multiple networks analysis. Cybergeo, 528. Retrieved from http://cybergeo.revues.org/23603 doi: $10.4000 /$ cybergeo.23603

Gastner, M. T., \& Newman M. E. (2006). The spatial structure of networks. The European Physical Journal B, 49, 247-252. doi:10.1140/epjb/e2006-00046-8

Gleyze, J. F. (2007). Effets spatiaux et effets réseau dans l'évaluation d'indicateurs sur les nœuds d'un réseau d'infrastructure [Making allowances for spatial and network effects when assessing indicators of infrastructure network nodes]. Cybergeo, 370, Retrieved from http://cybergeo. revues.org/5532 doi:10.4000/cybergeo.5532

Glückler, J. (2013). Knowledge, networks and space: Connectivity and the problem of non-interactive learning. Regional Studies, 47, 880-894. doi:10.1080/00343404.2013.779659

Gorman, S. P., Patuelli, R., Reggiani, A., Nijkam, P., Kulkarni, R., \& Haag, G. (2007). An application of complex network theory to German commuting patterns. In T. L. Friesz (Ed.), Network science, nonlinear science and infrastructure systems (pp. 167-185). International Series in Operations Research \& Management Science: Vol. 102. New York: Springer. doi:10.1007/0-387-71134-1_8

Gowan, R. \& Brantner, F. (2008). A global force for human rights? An audit of european power at the UN. European Council on Foreign Relations, Policy paper 2. http://ecfr.eu/content/entry/ the_european_union_at_the_united_nations

Grabher, G. (2006). Trading routes, bypasses, and risky intersections: Mapping the travels of 'networks' between economic sociology and economic geography. Progress in Human Geography, 30, 163-189. doi:10.1191/0309132506ph600oa

Hafner-Burton, E. M., Kahler, M., \& Montgomery, A. H. (2009). Network analysis for international relations. International Organization, 63, 559-592. doi:10.1017/S0020818309090195

Haggett, P., \& Chorley, R. J. (1969). Network analysis in geography. London: Edward Arnold.

Henry, N., Fekete, J. D., \& McGuffin, M. J. (2007). NodeTrix: A hybrid visualization of social networks. IEEE Transactions on Visualization and Computer Graphics, 13, 1302-1309. doi:10.1109/TVCG.2007.70582

Kansky, K. J. (1963). Structure of transportation networks: Relationships between network and regional characteristics (Doctoral dissertation). Research papers: Vol. 84. Chicago: University of Chicago.

Kissack, R. (2007). European Union member state coordination in the United Nations system: How to measure cohesion. CFSP Forum, 5(2), 3-5.

Lijphart, A. (1963). The analysis of bloc voting in the General Assembly: A critique and a proposal. The American Political Science Review, 57, 902-917. doi:10.2307/1952608

Maisonobe, M. (2013). Diffusion et structuration spatiale d'une question de recherche en biologie moléculaire [Diffusion and spatial structuring of a research question in molecular biology]. M@ppemonde, 110. Retrieved from http://mappemonde.mgm.fr/num38/articles/art13202.html

Mansfield, E. D., \& Milner, H. V. (1999). The new wave of regionalism. International Organization, 53, 589-627. doi:10.1162/002081899551002 
Mathis, P. (Ed.). (2003). Graphes et réseaux, modélisation multi-niveau [Graphs and networks, multilevel modeling]. Paris: Hermes Lavoisier.

Nystuen, J. D., \& Dacey, M. F. (1961). A graph theory interpretation of nodal regions. Papers of the Regional Science Association, 7, 29-42. doi:10.1007/BF01969070

Rozenblat, C., \& Mélançon, G. (2007). A small world perspective on urban systems. In F. Bavaud \& C. Mager (Eds.), Handbook of theoretical and quantitative geography (pp. 431-467). Lausanne: University of Lausanne. Retrieved from http://wp.unil.ch/citadyne-news/ files/2012/05/ROZENBLAT_MELANCON_CITADYNE_2009.pdf

Song, W. (2007). Regionalisation, inter-regional cooperation and global governance. Asia Europe Journal, 5, 67-82. doi:10.1007/s10308-006-0094-y

Tobler, W. (1970). A computer movie simulating urban growth in the Detroit region. Economic Geography, 46, 234-240. doi:10.2307/143141

Van Hamme, G., \& Grasland, C. (Ed.). (2011). Statistical toolbox for flow and network analysis. EuroBroadMap working paper. Retrieved from http://halshs.archives-ouvertes.fr/ docs/00/65/45/32/PDF/EWP_flows_networks_toolbox.pdf

Van Hamme, G., \& Pion, G. (2012). The relevance of the world-system approach in the area of globalization of economic flows and networks. Geografiska Annaler: Series B, Human Geography, 94, 65-82. doi:10.1111/j.1468-0467.2012.00396.x

Voeten, E. (2000). Clashes in the Assembly. International Organization, 54(2), 185-215. Retrieved from http://journals.cambridge.org/action/displayAbstract?fromPage=online\&aid=164773\&fi leId=S0020818300440981

Open Access This chapter is distributed under the terms of the Creative Commons Attribution 4.0 International License (http://creativecommons.org/licenses/by/4.0/), which permits use, duplication, adaptation, distribution and reproduction in any medium or format, as long as you give appropriate credit to the original author(s) and the source, provide a link to the Creative Commons license and indicate if changes were made.

The images or other third party material in this chapter are included in the work's Creative Commons license, unless indicated otherwise in the credit line; if such material is not included in the work's Creative Commons license and the respective action is not permitted by statutory regulation, users will need to obtain permission from the license holder to duplicate, adapt or reproduce the material. 